\title{
The impact on work-related stress of mental health teams following team-based learning on clinical risk management
}

\author{
S. B. SHARKEY ${ }^{1} \&$ A. SHARPLES ${ }^{2}$ \\ ${ }^{1}$ Department of Nursing \& Midwifery, University of Stirling, Highland Campus, Inverness, and ${ }^{2}$ Institute of Health \\ and Community Studies, Bournemouth University, Bournemouth, UK
}

Correspondence:

Siobhan B Sharkey

Department of Nursing \&

Midwifery

University of Stirling

Highland Campus

Old Perth Road

Inverness IV2 3FG

$U K$

s.b.sharkey@stir.ac.uk

\section{SHARKEY S. B. \& SHARPLES A. (2002) Journal of Psychiatric and Mental Health Nursing 9, ••-••• \\ The impact on work-related stress of mental health teams following team-based learning on clinical risk management}

\begin{abstract}
Risk management is viewed as a systematic process based on multiprofessional and multi-agency decision-making. A learning pack was developed as part of a team-based learning project aiming to encourage and develop collaborative working practice. This brought different professionals and agencies working in mental health together to learn. There is little doubt that mental health practice is a source of stress for practitioners. Apart from the stress associated with managing 'risky' situations, risk management is also a relatively new concept. This can increase stress around ability to cope, both on an individual practitioner level and in teams. This article reports the impact that the learning pack had on team members' stress, specifically work-related stress. A range of scales were used to measure change in stress and results demonstrated reduced work-related pressure in a number of areas following the learning. The implications for team learning in relation to clinical risk management are discussed in light of the findings.
\end{abstract}

Keywords: clinical risk, evaluation, pre and post measures, team-based learning, workrelated stress

Accepted for publication: 9 July 2002

\section{Introduction}

A learning pack on risk management in mental health was developed for use with clinical mental health teams and brought different professionals and agencies together to learn. The pack included a range of activities designed to enable participants to safely discuss and make decisions about risks in the mental healthcare context. The development of the pack commenced in Spring 1998 and was facilitated through collaboration with a large mental health provider in southern England, in conjunction with social services and the local voluntary sector working with people with serious and enduring mental health problems. The development of the learning pack is reported elsewhere
(Sharkey \& Sharples 2001, Sharkey et al. 2001). This article reports the impact that the learning pack had on team members' stress, specifically work-related stress. (The term 'risk management' is used throughout to include assessment and management.)

\section{The pack}

The draft learning pack comprised six sections, each of which had a corresponding group workshop facilitated by mental health trainers. A facilitator's (trainer's) pack was also provided. Each group workshop comprised a mix of facilitator-directed sessions, participant-led group discussions, presentations and feedback, as well as activities and 
reading between workshops. Group workshops had a minimum of 4 weeks between them. Facilitators provided advice on clinically based activities between workshops. Group workshops lasted approximately $3 \frac{1}{2}$ hours. The learning activity occurred in two localities and was run by the same two facilitators.

\section{Evaluation phase}

Following the development of the learning pack (Sharkey \& Sharples 2001) a 6-month evaluation (pilot) was carried out.

The evaluation phase of the study had a number of aims, including identifying any impact on occupational stress of team members and any changes in knowledge and skills. The evaluation also aimed to identify problems with the delivery of the pack. This article reports the findings relating to occupational stress; other findings are reported elsewhere (Sharkey et al. 2001).

\section{Models and sources of stress}

The research team were interested in whether or not the learning pack helped reduce work-related stress among the mental health teams. Cooper's model of the dynamics of work stress has been cited as particularly useful in linking details of work stressors and their individual and organizational outcomes. (Cooper \& Marshall 1976, Cooper 1981, Cox 1993) This model identifies sources of stress as: intrinsic to the job; role in the organization; relationships at work; career development; organizational structure and climate and home-work interface. (Cooper 1981) Kirkcaldy \& Martin (2000) also emphasize the usefulness of Cooper's stress-model (Cooper et al. 1988), which identifies causes of work-related stress to include organizational roles, relationships with others, organizational structures and climate, where the effects of stressors can manifest themselves in mental and physical health problems and in lowered job satisfaction.

Fagin \& Bartlett (1995) and Fagin et al. (1995) provide a useful model of stress that 'captures the dynamic and temporal elements of stress and sees it as a struggle between coping strategies and external "real world" pressures which impinge on individuals and have subjective and sometimes physical consequence' (Fagin \& Bartlett 1995, p. 76). Their model is based on that proposed by Cooper et al. (1988), who developed the occupational stress indicator. Fagin et al. (1995) caution against assuming a causal link between external demands and stress. They propose that causes are often determined by the interaction of many components, both the intrinsic (what people do) and extrinsic (aspects of the job such as management structures, goals, conditions, relationships) factors as well as the temporal aspects. These factors are well documented in the literature (Numberof \& Abrams 1984, Cooper \& Mitchell 1990, Carson et al. 1997, 1999, Baillon et al. 1999, Kirkcaldy \& Martin 2000). Fagin \& Bartlett (1995) also factor in the role of personality, particularly those aspects that influence confidence and esteem (increased stress being linked to type A personality). Moore \& Cooper (1996) have found, for example, that GPs have more type A personalities than other health professionals, making them particularly vulnerable to stress. They go on to suggest that strategies such as 'insight-orientated training' need to be more fully understood in light of the particular stressors of working in mental health.

Many studies report similarities in the sources of stress and burnout in healthcare staff. Among these are issues relating to team relationships, type of clinical area and context of work, conflict between home and work pressures and confidence and competence in undertaking new roles and areas of care (Kennedy \& Grey 1997, Dawkins et al. 1985, Nolan \& Cushway 1995, Michie et al. 1996). Recently, Wall et al. (1997) found that health service workers reported significantly higher levels of psychiatric disorder associated with stress than the general population. In addition, nursing staff have been found to have the highest levels of pressure and high levels of psychiatric morbidity. (Rees \& Cooper 1992, Wall et al. 1997, Baillon et al. 1999). Kirby \& Pollock (1995) discuss the links between work pressure, lack of involvement in decision-making and a 'distancing' from personal involvement with clients and they link increased job satisfaction and good relationships to lower stress.

Moore \& Cooper (1996) suggest that professionals who work in emotionally demanding environments have exacerbated experiences of stress and strain, and that mental health professionals are particularly vulnerable to severe emotional exhaustion and psychological tension, which they suggest are qualitatively different from other organizational stressors. They discuss the 'big three' in relation to an interactive model of stress: home, work and personality. Kirkcaldy \& Martin (2000), in examining and assessing multiple job-related variables found that nursing professionals, for example, perceive most stress to be related to confidence and competency in role, home-work conflict and organizational involvement. They also found that stress is closely associated with demands imposed in interpersonal relationships.

There is little doubt of the intrinsic components of mental health practice as a source of stress for practitioners. Dunn \& Ritter (1995) discuss stress moderators in relation to psychiatric nurses. They examine the role of social support, team support and role clarity in mitigating the stress- 
ful effects of violence against staff or threats of violence. In examining the literature, they revealed uncertainty as to whether organizational support reduced stress. Dewe (1987) also examined the relationship between stressors and stress in over 2000 New Zealand nurses, identifying coping strategies used by nurses. He identified six dimensions: problem-orientated behaviours; unwinding strategies (in relation to colleagues); keeping problems to oneself; acceptance; resignation; and avoidance behaviours such as smoking, and drinking alcohol, tea and coffee. Edwards et al. $(2000,2001)$, in relation to community teams, link levels of stress to increased workload, administrative duties and lack of resources. For community mental health nurses in particular, they identify inappropriate referrals, safety issues, role conflict, role ambiguity and lack of support. In a companion report to the study, Burnard et al. (2000, p. 526) reported an emerging picture of community mental health nurses:

... who perceive themselves to be overworked, struggling with considerable paperwork and administrative issues, having both too many clients and serious concerns about their client group.

Sources of stress have also been identified more directly by Coffey (1999) as 'managing difficult patients' and by Whittington \& Wykes (1992) as minor acts of violence. Burnard et al. (2000) also identified client-centred issues such as concerns about safety of clients, nurses' safety and dealing with suicidal behaviour. They conclude that effects of stress can vary between mental and physical health problems and reduced job satisfaction. High absenteeism, poor job performance and reduced effectiveness are among the organizational consequences of stress.

Apart from the stress associated with managing 'risky' situations, crisis and dangerous clinical and social conditions, risk management is also a relatively new concept within which practitioners are being encouraged to frame their working practices. Dealing with new work systems, perhaps perceived as an employer's agenda, can raise practitioner anxiety around ability to cope, both on an individual level and in teams.

\section{Education and risk management}

Arguably, effective risk management systems should have a beneficial effect on practitioners working together in clinical and community settings; however, the role and impact of education in improving effectiveness or reducing workrelated stress, is unclear (Department of Health 1998, Jordan et al. 1999). Brown et al. (1995) in a study of community psychiatric nurses' stressors, demonstrated that for the group of CPNs surveyed, not having an ENB course in community psychiatric nursing was predictive of higher GHQ (general health questionnaire) scores, indicating increased mental and physical health problems. In addition, a number of factors have been identified in relation to stress. For example, work restructuring, better support and shorter hours were noted to reduce stress for junior doctors (Payne 1999). Improved clinical supervision and targeted education have also been identified as effective. (Moore \& Cooper 1996, Cresswell \& Firth-Cozens 1999) Effectiveness of teamwork was also found to be positively related to job satisfaction and mental health of team members (Carter \& West 1999).

Risk management is dependent on good communication between team members, clear identification of client needs and available resources, including which professionals need to do what, when and how often. Managing crisis and risk brings mental health practitioners into situations that can have negative consequences for both themselves and service users, for example violence, physical safety issues, verbal threats and distressing events such as suicide or self-harm. Education about risk management should therefore aim to bolster the coping mechanisms that practitioners use to deal with these sorts of stressful situations. Jones \& Johnson (2000), when discussing programmes to reduce 6 stress in clinicians, recommend multilevel programmes that attempt to reduce problematic elements of the psychosocial work environment. They identify a range of adaptive changes in problem-solving, self-management skills, affective well-being and work performance as a result of educational interventions. Parry-Jones et al. (1998) suggest that being able to control stress factors, such as heavy workloads and caseloads, work relationships, aspects of relationships with service users, and lack of time, staff and resources, as well as administrative activities, are important aspects in stress reduction. The learning pack aimed to facilitate development of individual and team skills in coping with stressful events at work and was evaluated on the extent to which it reduced work-related stress for the group of learners.

In summary, key factors in relation to role and performance include stress levels, coping strategies and relationships with colleagues. It makes sense therefore to have expectations that education and learning about clinical risk assessment and management will have a positive impact on stress levels and coping (among other outcomes such as changes in practices). Following a period of learning in relation to risk management, it was anticipated that a reduction in stress related to pressures and coping at work, would be found within the multidisciplinary team. In keeping with the aims of the study the research question for this phase of the evaluation is: Is there observed change in the multidisciplinary team across a number of dimensions 
jpm_534.fm

relating to coping, stress and work, following the learning period?

\section{Aim}

The aim of the research reported here was to describe any impact on the work-related stress of mental health teams using the learning pack.

\section{Design and methods}

Robson (2000) talks about the methodological difficulty when one wants to move simply from saying that there has been a change, to claiming the change can be attributable to the intervention itself and not some other cause. In the current study it was difficult to set up a controlled experiment. Random assignment was not practical as it was felt that the likelihood of all members of a locality team agreeing to participate would be reduced if there was a possibility of non-assignment to the learning opportunity (Robson 1993) Teams needed to know what they were committing to (Frankfort-Nachmias \& Nachmias 1996, Robson 2000) Therefore, a quasi-experimental approach was adopted for this phase of the study, using pre and post measures, which enabled a measure of change, albeit subject to the methodological difficulties highlighted. As empirical generalizability was not an objective, it was felt that this approach was acceptable to gain a picture of change within the context of the study. Rigorous operationalization of measures enhanced trustworthiness and accuracy of the findings.

\section{Sample}

The sample consisted of two locality teams, each from a different site within an NHS Trust. Sampling was selfselective in that each locality team in the Trust was provided with information (including information sheets for each member of the team) about the research and invited to participate. Team leaders then conveyed their willingness to participate to the researchers on behalf of their team. Members of two locality teams volunteered. These teams were made up of nurses, psychiatrists, occupational therapists, psychologists and social workers from acute inpatient and community settings.

A series of information-giving presentations about the learning pack and the evaluation were made within the Trust (this amounted to county-wide presentations as the Trust spanned a large rural setting). The aim was to include as many qualified practitioners as possible from each locality team. Forty-one participants in all were initially recruited between the two teams.

\section{Measures}

Occupational stress indicator (OSI) (Cooper et al. 1988) The OSI has been used in a wide range of settings, including healthcare, to measure occupational stress and provides a useful measure for the impact of the learning pack. It is a reliable and validated scale (Robertson et al. 1990) and has been used extensively as a research tool in surveys (Onyett et al. 1997), in pre and post (before and after) studies (Reid \& Moss 1999) and as a measure of change over time (Proctor et al. 1998, Baillon et al. 1999, Kirkcaldy \& Martin 2000).

The indicator comprises a biographical questionnaire and six subscales, each using a six-point Likert scale. The OSI is built on a model of stress in keeping with the aims of the evaluation. (Cooper et al. 1994) Combined sample means derived from raw data collected during over 20 studies using the OSI (sample $>7000$ ) are available for comparison purposes. (Cooper et al. 1994).

Healthcare-related work pressure scale (adapted from the nurse stress index, NSI, Harris 1989)

Given one foci of the evaluation was impact on workrelated stress, it was decided to administer an additional measure to validate the research findings in relation to stress by comparing the findings pre and post from the OSI work-related pressure scale.

For this purpose the work-related subscales from the nurse stress index (NSI) were chosen. The NSI was developed as a 30-item self-report method of identifying sources of stress for groups of senior nurses. The NSI was found to be reliable and have reasonable construct-validity in a study of 117 front-line nurses (Cooper \& Mitchell 1990). The NSI comprises six subscales and uses a five-point Likert-type rating scale with $1=$ not at all pressured and $5=$ extremely pressured. The 'managing the workload (1) and (2)' and 'dealing with patients and relatives' subscales were used in the current study. The word nursing was replaced by the word practice within the 'managing the workload (2)' scale. Higher scores indicate higher workrelated pressure.

\section{Operationalization and administration of measures}

Participants were coded prior to administration of pre measures. The measures were administered according to the instructions within the OSI management pack (Cooper et al. 1988). The recommended administration procedure was followed, ensuring there were similar conditions for each participant. The OSI is self-administered and takes approximately 45 minutes to complete. The shortened NSI was administered along with the OSI during 1-hour ses- 
sions. Pre and post measures were administered within 8 weeks before and after the learning intervention. The piloting of the pack (learning intervention) lasted for 6 months, with six trainer-led workshops approximately 1 month apart.

\section{Ethical considerations}

Once teams identified themselves as willing to participate, individual team members were asked to give consent to participation. Participants were reassured that measures would be reported anonymously and that the responses would be analysed by group only. Ethical permission for the study was granted by the Trust ethics committee. A project steering group provided peer review for the study.

\section{Analysis}

Quantitative data for pre and post measures were analysed using descriptive statistics (including 95\% confidence intervals of the difference). Data were examined for normality. Parametric tests (paired $t$-test) were used for those items that were normally distributed, non-parametric tests (Wilcoxon signed rank test) were used for items not normally distributed. Significance levels were set at $P=0.05$. (Statistical Package for Social Sciences, SPSS Version 10; Munro 2001) Not all respondents completed all items for the OSI questionnaires. In the event of a missed response, scale calculation was completed by inserting a 'neutral' score of 3.5. This approach was deemed acceptable due to the very small number $(0.27 \%)$ of missing items (Baillon et al. 1999).

\section{Results}

Of the initial 41 participants recruited into the evaluation (pilot) phase of the study, all 41 completed the pre measures. However, only 32 started the learning pack and 27 completed the pack and subsequently the post measures. Analyses were carried out on the 27 participants who completed both the pre and post measures. Responses were not broken down in terms of gender or individual professional group as the aims of the study involved an interest in whole group (team) impact. Attrition did not affect the spread of occupations represented in the study. Means, standard deviations and confidence intervals for each scale in the OSI and the NSI scales are reported in Tables 1 and 2 (* = significant).

In comparison with available norms and means from similar studies, mean scores for pre measures on the six scales in the OSI were on a par with other healthcare worker norms and slightly higher than reported norms for white collar workers (Cooper et al. 1994). When compared with a similar mixed group of health professionals working in a specialist psychiatric elderly unit (Baillon et al. 1999), the means indicate corresponding sources of stress, better locus of control, similar job satisfaction, less frequent type A behaviour, better mental and worse physical health. Comparing pre and post learning scores for the OSI sources of stress subscale suggests that there was a general decrease in many sources of stress, with the items 'factors intrinsic to the job' $(\mathrm{z}=-2.216 ; P=0.027)$ and 'the managerial role' $(t=2.352$; d.f. $=26 ; P=0.027)$ showing significant difference. Although no significant change was shown in any of the other subscales in the OSI, the 'events around you' subscale means were also all lower at post measures, suggesting an increase in perceived loci of control. The mental health subscale mean was also lower at post measure, suggesting improved mental health. Interestingly, lower means at post measures are also observed for the job satisfaction subscale, suggesting less satisfaction.

Scores for the NSI (nurse stress index) 'work-related pressure' scales all show a lowering of item means at post measure. This suggests a general decrease in work-related pressure, with two items showing significant difference following the intervention, 'fluctuations in workload' $(t=3.03$; d.f. $=26 ; P=0.05)$ and 'dealing with relatives' $(t=2.739$; d.f. $=25 ; P=0.011)$, and three items showing highly significant difference, 'difficulty in dealing with aggressive people' ( $t=5.75$; d.f. $=26 ; P<0.001)$, 'difficult patients' $(t=4.441$; d.f. $=26 ; P<0.001)$ and 'involvement in life and death situations' $(t=3.783$; d.f. $=26$; $P=0.001)$.

\section{Discussion}

One of the aims of the research was to produce a learning opportunity and describe its impact on clinical teams. Using a range of measures relating to perception of workrelated stress, work coping strategies and control the research was able to demonstrate impact in a number of areas.

Results from OSI and NSI measures before and after the learning intervention suggest that there were significant changes in a number of areas in relation to participants' experiences of stress within 2 months before and after they undertook the clinical risk learning.

A number of areas of change in measurement means warrant further comment. In particular there appears to have been a clear impact on work-related stress. All of the NSI work pressure subscales showed a decrease in mean scores, suggesting a lowering of work-related stress. This is particularly interesting when set alongside the changes in the OSI subscale, sources of stress. All demonstrated a low- 
jpm_534.fm

S. B. Sharkey \& A. Sharples

Table 1

Mean OSI scores for the combined groups at pre- and post-learning intervention. Combined sample means derived from raw data collected during over 20 studies using the OSI (sample > 7000), which are available for comparison purposes (Cooper et al. 1994)

\begin{tabular}{|c|c|c|c|c|c|}
\hline \multirow[b]{2}{*}{ OSI subscales } & \multicolumn{2}{|c|}{ Pre-measures $(n=27)$} & \multicolumn{2}{|c|}{ Post-measures $(n=27)$} & \multirow[b]{2}{*}{$\mathrm{Cl}(95 \%)$} \\
\hline & Mean & SD & Mean & SD & \\
\hline \multicolumn{6}{|c|}{ Sources of stress (higher score $=$ more frequent felt source) } \\
\hline Factors intrinsic to the job & 31.81 & 6.00 & 29.92 & 2.93 & $-0.22-4.19 *$ \\
\hline The managerial role & 40.04 & 8.19 & 37.41 & 7.21 & $0.33-4.93 *$ \\
\hline Relationships with other people & 32.33 & 6.78 & 31.44 & 5.69 & $-1.16-2.94$ \\
\hline Career and achievement & 29.85 & 6.07 & 27.85 & 5.95 & $-0.18-4.18$ \\
\hline Organizational structure/climate & 41.78 & 8.24 & 39.26 & 7.86 & $-6.24-5.10$ \\
\hline Home/work interface & 33.61 & 8.63 & 31.59 & 7.13 & $-0.62-4.66$ \\
\hline \multicolumn{6}{|c|}{ General behaviour (higher score more = frequent type $A$ ) } \\
\hline Attitude to living & 20.41 & 4.13 & 20.33 & 3.42 & $-0.93-1.08$ \\
\hline Style of behaviour & 15.89 & 3.75 & 16.09 & 2.44 & $-1.25-0.84$ \\
\hline Ambitions & 10.74 & 1.72 & 10.30 & 1.46 & $-0.28-1.17$ \\
\hline Total type A & 46.89 & 7.45 & 46.98 & 5.97 & $-1.75-1.56$ \\
\hline \multicolumn{6}{|c|}{ Events around you (higher score = perception of less control) } \\
\hline Management processes & 14.20 & 1.56 & 13.85 & 1.79 & $-0.38-1.09$ \\
\hline Individual influences & 10.19 & 1.52 & 9.91 & 1.58 & $-0.72-1.27$ \\
\hline Total locus of control & 43.06 & 4.39 & 42.20 & 4.06 & $-0.72-2.42$ \\
\hline \multicolumn{6}{|c|}{ Coping with stress (higher score more = frequent use as coping source) } \\
\hline Social support & 17.11 & 2.87 & 16.85 & 2.86 & $-0.64-1.16$ \\
\hline Task strategies & 26.70 & 3.78 & 26.44 & 2.65 & $-1.16-1.68$ \\
\hline Logic & 12.81 & 1.42 & 12.41 & 1.78 & $-0.13-0.95$ \\
\hline Home and work relationship & 16.67 & 3.64 & 16.78 & 2.69 & $-0.98-0.76$ \\
\hline Time & 14.85 & 1.61 & 15.07 & 1.57 & $-0.88-0.44$ \\
\hline Involvement & 23.04 & 2.72 & 23.67 & 2.47 & $-1.90-0.64$ \\
\hline \multicolumn{6}{|c|}{ Job satisfaction (higher score higher = satisfaction) } \\
\hline Achievement/value and growth & 23.33 & 3.96 & 23.87 & 4.41 & $-2.52-1.45$ \\
\hline The job itself & 16.19 & 2.79 & 17.24 & 2.52 & $-2.13-2.27$ \\
\hline Organizational design and structure & 18.11 & 2.90 & 17.59 & 3.89 & $-0.79-1.82$ \\
\hline Total view of job satisfaction & 85.19 & 12.25 & 84.57 & 13.26 & $-4.79-6.01$ \\
\hline \multicolumn{6}{|c|}{ Current state of health (higher score = more ill health) } \\
\hline Mental & 51.48 & 12.78 & 49.15 & 12.20 & $-2.09-6.76$ \\
\hline Physical & 32.26 & 10.12 & 32.17 & 9.92 & $-3.91-4.09$ \\
\hline
\end{tabular}

$\star P<0.05$

ering of mean scores following the learning intervention, with significant change found in items 'Factors intrinsic to the job' and 'The managerial role', again indicating a reduction in the extent to which work was regarded as a source of stress. Interestingly, in contrast to our findings, Proctor et al. (1998) found a general increase in pressure in the OSI scale 'sources of stress' (work-related pressures) experienced by care staff (control and intervention) following a period of training over 6 months. However, there was no significant difference between baseline and follow-up scores. They go on to suggest that based on their overall findings, including measures of general health (GHQ), lack of support and training in coping with a demanding and difficult job is a major source of stress for many care staff in nursing and residential homes. Given the apparently positive impact on sources of stress following training in the current study, it is suggested that this need for training and support is as important for mixed mental health teams as it is for inpatient or residential settings.

Given the topic of the learning intervention, it is also worth noting that significant changes in the NSI workrelated scale were found in the following items: 'difficulty in dealing with aggressive people', 'difficult patients', 'involvement with life and death situations' and 'dealing with relatives', the first two items showing highly significant change. The aims of the study in relation to the learning were to try to make a difference in the way in which teams understood and handled clinical risk. It is encouraging therefore within the limitations of the design of the study, to observe significant change within areas directly relating to working both with difficult patients and the risk area of aggression. Although this was a small non- 
Table 2

Mean NSI scores for the combined groups at pre- and post-learning intervention

\begin{tabular}{|c|c|c|c|c|c|}
\hline \multirow[b]{2}{*}{ NSI scale, work-pressure subscales } & \multicolumn{2}{|c|}{$\begin{array}{l}\text { Pre-measures } \\
(n=27)\end{array}$} & \multicolumn{2}{|c|}{$\begin{array}{l}\text { Post-measures } \\
(n=27)\end{array}$} & \multirow[b]{2}{*}{$\mathrm{Cl}(95 \%)$} \\
\hline & Mean & SD & Mean & SD & \\
\hline I have too little time in which to do what is expected of me & 3.56 & 0.97 & 3.15 & 1.03 & $-4.8-0.86$ \\
\hline The demands of others for my time at work are in conflict & 3.00 & 1.00 & 2.93 & 1.14 & $-0.34-0.48$ \\
\hline I spend my time fighting fires rather than working to a plan & 2.67 & 1.07 & 2.33 & 0.96 & $-4.7-0.71$ \\
\hline Fluctuations in workload & 3.22 & 0.97 & 2.59 & 0.97 & $0.20-1.1 *$ \\
\hline Management expects me to interrupt my work for new priorities & 3.08 & 1.20 & 2.69 & 1.26 & $-0.14-0.91$ \\
\hline Deciding priorities & 2.63 & 0.88 & 2.30 & 0.95 & $-0.12-0.79$ \\
\hline My practice and administrative roles conflict & 3.12 & 0.91 & 2.85 & 0.92 & $-0.10-0.64$ \\
\hline Shortage of essential resources & 3.33 & 1.24 & 3.11 & 1.22 & $-0.27-0.72$ \\
\hline Difficulty in dealing with aggressive people & 2.81 & 1.14 & 1.96 & 0.85 & $0.55-1.2 *$ \\
\hline Difficult patients & 2.85 & 1.10 & 2.15 & 0.99 & $0.38-1.0 *$ \\
\hline Bereavement counselling & 2.19 & 0.98 & 2.00 & 1.02 & $-0.25-0.64$ \\
\hline Dealing with relatives & 2.15 & 0.88 & 1.69 & 0.68 & $0.11-0.81$ * \\
\hline Lack of privacy & 2.44 & 1.42 & 2.00 & 1.07 & $-9.7-0.99$ \\
\hline Poor physical working conditions & 2.70 & 1.32 & 2.26 & 1.02 & $-0.14-1.0$ \\
\hline
\end{tabular}

controlled study, with the associated dangers of being under-powered, the degree of change in these two items in particular, indicates that there has been real change in this area. Indeed, the overall trend towards a reduction in work-related stress across all items in the NSI and OSI scales points to a meaningful impact. A range of items across both the OSI and the NSI scales have scores that are likely to indicate a type II error: when sample sizes are small it is likely that real underlying differences between groups (time one and time two) are not detected. Examining the confidence intervals for these items, where the minus figure is very close to zero, suggests significance but with the study being under-powered (Munro 2001).

Other subscales in the OSI also demonstrate interesting changes. The job satisfaction subscale, although not demonstrating any significant changes, does demonstrate a lowering of means across four items: 'organizational design and structure', 'organizational processes', 'personal relationships' and 'total view of job satisfaction'. It is interesting to observe a lowering of satisfaction with work, while at the same time observing that work is perceived as less stressful. Participants appear to be expressing that they are less satisfied with how their work settings are organized and run. This lowering may be the result of increased knowledge about the importance of good communication systems and documentation in managing risk. Increased expectation about one's own work systems and processes and increased concern over the gap between what is needed and what exists may have led to increased dissatisfaction among participants. Participants also reported an increase in feelings of control in relation to events around them: 'organizational forces', 'management forces' and 'individ- ual influences'. Although not significant, this overall increase in feelings of control may again be a result of having increased knowledge and skills in relation to the management of clinical risk. Taking all the work-related changes together provides an indication that the learning did have some impact, in some cases significant impact, on participants. Wall et al. (1997) suggest that organizations have a role to play in reducing stress and that developing and supporting teams can have an impact. Firth-Cozens \& Payne (1999) suggest that good management, improved communication, culture change and developing good team leaders can also play a part in lowering stress. Education has an important role to play in providing an opportunity for team members to increase knowledge and skills in key areas such as communication and in 'practising' working together in a safe and supportive way. Vincent (1999) also suggests that good communication, co-operation and training for staff are important aspects in the healthy development of organizations. These sorts of opportunities, such as that afforded by the clinical risk learning pack, can form the medium through which change can occur.

Other OSI scales demonstrate more modest or variable change between items. There were variable mean changes observed in the general behaviour and coping with stress subscales, indicating little trend within these domains. There also appeared to be little impact in relation to 'physical health', although 'mental health' appears to have improved, although not significantly, following the learning.

Additional outcomes for the study are more fully described in Sharkey \& Sharples (2001). Feedback from the pre and post measures, the evaluation questionnaires 
and a dissemination conference, were used to further inform and shape the learning pack, which is now complete and in use (Sharkey et al. 2001). The pack comprises an introduction to risk followed by four facilitator-led group workshops focusing on: violence; suicide and self-harm; vulnerability and neglect; and reviewing the pack and action planning.

\section{Limitations}

This was a small, non-controlled study and therefore nongeneralizable. Nevertheless, the research team has been able to suggest that the pack made a positive rather than negative impact on participants. A 6-month follow-up of measures to establish any sustained change would have increased the validity of the findings. There were difficulties getting 'busy professionals' together to complete the pre and post measures. The research team acknowledges that the project required intensive input over time from the participants and this may have contributed to attrition. However, at a dissemination conference participants provided feedback that they viewed participation in the project as a positive experience and valued being part of a research project. Finally, one of the participating teams in the study experienced a significant traumatic event within the team during the learning period. The nature of this event may have had a negative impact on the team, thus adding to the complexity of the factors that may have influenced change and been reflected in post measures following the learning.

\section{Conclusion}

Overall there does appear to have been an impact following the learning, particularly in relation to risk-related aspects of work and the way in which work is perceived as a source of stress. Given the small numbers in the study (and the likelihood that it was under-powered), there was an overall trend pointing to a reduction in work-related pressure (subscales OSI and NSI), with significant change in some items, suggesting real impact in these areas. It is worth noting that the use of the OSI, which facilitates a broad range of measures relating to stress, provides an opportunity to work across and within professional groups. Inter-relatedness between team members is an important aspect of effective practice and it is felt that using a measure that acknowledges the team context of the work environment is crucial. Ironically, although not unexpectedly, the learning also appears to have increased dissatisfaction with work. This is an important issue for both educationalists and employers: increased awareness as a result of learning can lead to dissatisfaction both with an organization and with one's own capabilities. Strategies such as follow-up sessions and supervision could mitigate this effect.

It is impossible to be conclusive about the way in which the learning pack led to a reduction in work-related stress given the small size of the study, its non-controlled nature and the potential impact on participants from a multiplicity of sources. Nevertheless, it is possible to suggest that learning about risk management in the mode described in the current study, that is, team and clinically orientated, had a positive impact on participants in reducing the extent to which they felt work was a source of stress. This is an important outcome for any piece of learning, in enabling a workforce to cope with a very demanding, difficult and complex role.

\section{Acknowledgements}

The research was partially funded by NHS Executive $S \&$ W Region. The researchers would like to thank the participating teams and host Trust. Specific thanks also go to Dave Morris and Jon Wiggans, who both contributed to the development of the pack and facilitated sessions. The research would not have been possible without their contribution and enthusiasm. Thanks also go to Holly Crossen-White and Sarah Gibson, co-researchers on the project, and to Peter White and Billy Lauder for statistical support.

\section{References}

Baillon S., Scothern G. \& Vickery L. (1999) Job satisfaction and stress in staff working in a specialist psychiatric unit for the elderly following relocation from a traditional psychiatric hospital setting. Journal of Nursing Management 7, 207-214.

Brown D., Leary J., Carson J., Bartlett H. \& Fagin L. (1995) Stress and the community mental health nurse: the development of a measure. Journal of Psychiatric and Mental Health Nursing 2, 9-12.

Burnard P., Edwards D., Fothergill A., Hannigan B. \& Coyle D. (2000) Community mental health nurses in Wales: self-reported stressors and coping strategies. Journal of Psychiatric and Mental Health Nursing 7, 523-528.

Coffey M. (1999) Stress and burnout in forensic community mental health nurses: an investigation of its causes and effects. Journal of Psychiatric and Mental Health Nursing 6, 433444.

Cooper C.L. (1981) Executive Families Under Stress. Prentice Hall, Englewood Cliffs, New Jersey.

Cooper C.L. \& Marshall J. (1976) Occupational sources of stress: a review of the literature relating to coronary heart disease and mental ill health. Journal of Occupational Psychology 49, 1128.

Cooper C.L. \& Mitchell S. (1990) Nurses under stress: a reliability and validity study of the NSI. Stress in the Community 6, 21-24. 
Cooper C.L., Sloan S.J. \& Williams S. (1988) The Occupational Stress Indicator. Windsor: NFER-NELSON, Windsor.

Cooper C.L., Sloan S.J. \& Williams S. (1994) Occupational Stress Indicator: Data Supplement. NFER-NELSON, Windsor.

Cox T. (1993) Stress research and stress management: putting theory to work. In: Contract Research Report, No. 61/1993 (ed.

Health \& Safety Executive), pp. xx-xx. HMSO/HSE, Norwich. Cresswell T. \& Firth-Cozens J. (1999) Child protection workers. In: Stress in Health Professionals (eds Firth-Cozens, J. \& Payne, R.131-146. Wiley \& Sons, Chichester.

10 Dawkins J.E., Depp F.C. \& Selzer (1985) Stress and the psychiatric nurse. Journal of Psychosocial Nursing and Mental Health Services 23, 9-15.

Department of Health (1998) A Review of Continuing Professional Development in Practice: a Report by the Chief Medical Officer. HMSO, London..

Dewe P.J. (1987) Identifying strategies nurses use to cope with work stress. Journal of Advanced Nursing 12, 489-497.

Dunn L.A. \& Ritter S.A. (1995) Stress in mental health nursing: a review of the literature. In: Stress and Coping in Mental Health Nursing (eds Carson, J., Fagin, L. \& Ritter, S.), pp. 29-46. Chapman \& Hall, London.

Edwards D., Burnard P., Coyle D., Fothergill A. \& Hannigan B. (2000) Stress and burnout in community mental health nursing: a review of the literature. Journal of Psychiatric and Mental Health Nursing 7, 7-14.

Edwards D., Burnard P., Coyle D., Fothergill A. \& Hannigan B. (2001) A stepwise multivariate analysis of factors that contribute to stress for health nurses working in the community. Journal of Advanced Nursing 36, 805-808.

Fagin L. \& Bartlett H. (1995) The Claybury CPN stress study: background and methodology. In: Stress and Coping in Mental Health Nursing (eds Carson, J., Fagin, L. \& Ritter, S.), pp. 6986. Chapman \& Hall, London.

Fagin L., Brown Bartlett H., Leary J. \& Carson J. (1995) The Claybury community psychiatric nurse stress study: is it more stressful to work in hospital or in the community? Journal of Advanced Nursing 22, 347-358.

Firth-Cozens J. \& Payne R. (1999) Stress in Health Professionals: Psychological and Organisational Causes and Interventions. John Wiley, Chichester.

Frankfort-Nachmias C. \& Nachmias D. (1996) Research Methods in the Social Sciences. Edward Arnold, London.

Harris P.E. (1989) The nurse stress index. Work and Stress 3, 335-346.

Jordan S., Coleman M., Hardy B. \& Hughes D. (1999) Assessing educational effectiveness: the impact of a specialist course on the delivery of care. Journal of Advanced Nursing 30, 796-807.

Kennedy P. \& Grey N. (1997) High pressure areas. Nursing Times 93, 26-28.

Kirby S.D. \& Pollock P.H. (1995) The relationship between a medium secure environment and occupational stress in forensic psychiatric nurses. Journal of Advanced Nursing 22, 862-867.

Kirkcaldy B.D. \& Martin T. (2000) Job stress and satisfaction among nurses: individual differences. Stress Medicine 16, 7789

Michie S., Ridour K. \& Johnston M. (1996) Stress in nursing and patients' satisfaction with health care. British Journal of Nursing 5, 1002-1006.
Mitchell J.C. (1983) Case and situation analysis. Sociological Review 31, 187-211.

Moore K.A. \& Cooper C.L. (1996) Stress in mental health professionals: a theoretical overview. International Journal of Social Psychiatry 42, 82-89.

Munro B.H. (2001) Statistical Methods for Health Care Research, 4th edn. Lippincott, Philadelphia.

Nolan P. \& Cushway D. (1995) A measurement tool for assessing stress among mental health nurses. Nursing Standard 9, 36-39.

Numberof R.E. \& Abrams M.N. (1984) Sources of stress among nurses: an empirical investigation. Journal of Human Stress X, 88-100.

Parry-Jones B., Grant G., McGrath M., Caldock K., Ramcharan P. \& Robinson C.A. (1998) Stress and job satisfaction among social workers, community nurses and community psychiatric nurses: implications for the care management model. Health and Social Care in the Community 6, 271-285.

Payne R. (1999) Stress at work: a conceptual framework. In: Stress in Health Professionals (eds Firth-Cozens, J. \& Payne, R.), pp. 3-16. Wiley \& Sons, Chichester.

Proctor R., Stanton-Powell H., Tarrier N. \& Burns A. (1998) The impact of training and support on stress among care staff in nursing and residential homes for the elderly. Journal of Mental Health 7, 59-70.

Rees D. \& Cooper C.L. (1992) Occupational stress in health service workers in the UK. Stress in the Community 8, 79-90.

Reid N.G. \& Moss P.J. (1999) The impact of the New Deal: doctors' stress levels and their views. Stress Medicine 15, 9-15.

Robertson I.T., Cooper C.L. \& Williams J. (1990) The validity of the occupational stress indicator. Work and Stress 4, 29-39.

Robson C. (1993) Real World Research. Blackwell, Oxford.

Robson C. (2000) Small-Scale Evaluation. Sage, London.

Rosenberg M. (1965) Society and the Adolescent Self-Image. Princeton University Press, Princeton, New Jersey.

Schaufeli W.B. \& Peeters M. (2000) Job stress and burnout among correctional officers: a literature review. International Journal of Stress Management 7, 19-48.

Sharkey S. \& Sharples A. (2001) An approach to consensus building using the Delphi technique: developing a learning resource in mental health. Nurse Education Today 21, 398-408.

Sharkey S., Sharples A. \& Crossen-White H. (2001) Clinical Risk Management in Mental Health: Team Based Learning (the Development and Evaluation of a Learning Pack). Bournemouth University, Bournemouth.

Vincent C. (1999) Fallibility, uncertainty and the impact of mistakes and litigation. In: Stress in Health Professionals (eds Firth-Cozens, J. \& Payne, R.), pp. 63-76. Wiley \& Sons, Chichester.

Wall T.D., Bolden R.I., Borrill C.S., Carter A.J., Golya D.A., Hardy G.E., Haynes C.E., Rick J.E., Shapiro D.A. \& West M.A. (1997) Minor psychiatric disorder in NHS trust staff: occupational and gender differences. British Journal of Psychiatry 171, 519-523.

White C. \& Schweitzer R. (2000) The role of personality in the development and perpetuation of chronic fatigue syndrome. Journal of Psychosomatic Research 48, 515-524.

Whittington R. \& Wykes T. (1992) Staff strain and social support in a psychiatric hospital following assault by a patient. Journal of Advanced Nursing 17, 480-486. 


\section{AUTHOR QUERY FORM}

Journal: Journal of Psychiatric and Mental Health Nursing

Article: 534

Dear Author,

During the preparation of your manuscript for publication, the questions listed below have arisen. Please attend to these matters and return this form with your proof.

Many thanks for your assistance.

\begin{tabular}{|l|l|l|}
\hline Query References & \multicolumn{1}{|c|}{ Query } & Remarks \\
\hline 1 & $\begin{array}{l}\text { Numerof \& Abrams 1984 has been changed to Numberof \& } \\
\text { Abrams 1984 so that this citation matches the list }\end{array}$ & \\
\hline 2 & Carson et al. 1997 has not been included in the list & \\
\hline 3 & Carson et al. 1999 has not been included in the list & \\
\hline 4 & $\begin{array}{l}\text { Ballion et al. 1999 has been changed to Baillon et al. 1999 so that } \\
\text { this citation matches the list }\end{array}$ & \\
\hline 5 & Carter \& West 1999 has not been included in the list & \\
\hline 6 & Jones \& Johnson 2000 has not been included in the list & \\
\hline 7 & Onyett et al. 1997 has not been included in the list & \\
\hline 8 & $\begin{array}{l}\text { Baillion et al. 1999 has been changed to Baillon et al. 1999 so that } \\
\text { this citation matches the list }\end{array}$ & \\
\hline 9 & Au: Please supply the page range & \\
\hline 10 & Au: Please supply Selzer's initials & \\
\hline 11 & Mitchell 1983 has not been found in the text & \\
\hline 12 & Au: Volume number? & \\
\hline 13 & Au: Rosenberg 1965 has not been found in the text. & \\
\hline 14 & Schaufeli \& Peeters 2000 has not been found in the text & \\
\hline 15 & White \& Schweitzer 2000 has not been found in the text & \\
\hline
\end{tabular}




\section{Please correct and return this set}

Any errors in this proof which have been noticed by the printer's reader have been marked in green. If you see any more printer's errors, please mark them in red: there is no charge for correcting these mistakes. For your own alterations, please use black or blue or any colour other than green or red. Please use the proof correction marks shown below for all alterations and corrections.

\begin{tabular}{|c|c|c|}
\hline Instruction to printer & Textual mark & Marginal mark \\
\hline Leave unchanged & ... under matter to remain & Stet \\
\hline $\begin{array}{l}\text { Insert in text the matter } \\
\text { indicated in the margin }\end{array}$ & $h$ & $\begin{array}{l}\text { New matter followed by } \\
\boldsymbol{h}\end{array}$ \\
\hline Delete & $\mapsto$ through matter to be deleted & d] \\
\hline Delete and close up & E through matter to be deleted & मी \\
\hline $\begin{array}{l}\text { Substitute character or } \\
\text { substitute part of one or } \\
\text { more word(s) }\end{array}$ & $\begin{array}{l}\text { / through letter or } \mapsto \text { through } \\
\text { word }\end{array}$ & New letter or new word \\
\hline Change to italics & - under matter to be changed & س山 \\
\hline Change to capitals & $\equiv$ under matter to be changed & $\equiv$ \\
\hline Change to small capitals & $=$ under matter to be changed & $=$ \\
\hline Change to bold type & u under matter to be changed & $m$ \\
\hline Change to bold italic & $\bar{\approx}$ under matter to be changed & \\
\hline Change to lower case & Encircle matter to be changed & $\nRightarrow$ \\
\hline Change italic to upright type & (As above) & $\psi$ \\
\hline Insert 'superior' character & $\begin{array}{l}\text { / through character or } \wedge \text { where } \\
\text { required }\end{array}$ & $\begin{array}{l}y \text { under character } \\
\text { e.g. } y\end{array}$ \\
\hline Insert 'inferior' character & (As above) & $L$ over character e.g. $\frac{2}{2}$ \\
\hline Insert full stop & (As above & $\circ$ \\
\hline Insert comma & (As above) & , \\
\hline Insert single quotation marks & (As above) & $y$ and/or $y$ \\
\hline $\begin{array}{l}\text { Insert double quotation } \\
\text { marks }\end{array}$ & (As above) & 'y and/or $y$ \\
\hline Insert hyphen & (As above) & (4y) \\
\hline Start new paragraph & $r$ & $\sqrt{5}$ \\
\hline No new paragraph & 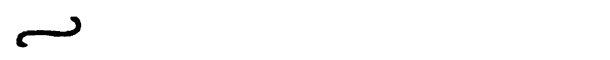 & 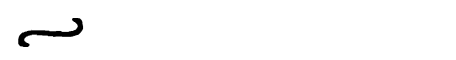 \\
\hline Transpose & $\sqrt{\sim}$ & $\sqrt{-1}$ \\
\hline Close up & linking $\approx$ letters & $=$ \\
\hline Insert space between letters & $\Lambda$ between letters affected & \# \\
\hline Insert space between words & $\boldsymbol{h}$ between words affected & \# \\
\hline Reduce space between letters & $\uparrow$ between letters affected & $T$ \\
\hline Reduce space between words & $\boldsymbol{\top}$ between words affected & \\
\hline
\end{tabular}

